\title{
Circulating LncRNAs Landscape as Potential Biomarkers in Breast Cancer
}

\author{
Zahra Pourramezan \\ Pasteur Institute of Iran \\ Fatemeh Akhavan Attar \\ Pasteur Institute of Iran \\ Maryam Yusefpour \\ Pasteur Institute of Iran \\ Masoumeh Azizi \\ Pasteur Institute of Iran \\ Mana Oloomi ( $\square$ manaoloomi@yahoo.com ) \\ Pasteur Institute of Iran
}

Research Article

Keywords: Breast cancer, Whole blood, Real-Time PCR, Long non-coding RNAs

Posted Date: April 30th, 2021

DOI: https://doi.org/10.21203/rs.3.rs-457164/v1

License: @ (1) This work is licensed under a Creative Commons Attribution 4.0 International License. Read Full License

Version of Record: A version of this preprint was published at Cancer Reports on October 23rd, 2022. See the published version at https://doi.org/10.1002/cnr2.1722. 


\section{Abstract}

The delay in diagnosis and treatment of breast cancer results in low survival rates and high mortality. Thus, it is essential to characterize new therapeutic targets and prognostic breast cancer biomarkers. The rising evidence suggested that long non-coding RNAs (IncRNAs) expression levels are deregulated in human cancers and can use as biomarkers for the rapid diagnosis of breast cancer. In the present study, a Quantitative Real-time polymerase chain reaction (qRT-PCR) technique was used to measure twenty oncogenic and tumor suppressor IncRNAs expression levels in whole blood samples of breast cancer patients and normal controls. Blood samples from 30 healthy women and 30 female breast cancer patients were collected. Then cDNA was synthesized from the extracted RNA blood. The expression level of IncRNAs measured and analyzed by LinReg PCR and REST software and the correlation between IncRNAs dysregulation and clinical characteristics and prognosis were also analyzed by SPSS software. The comparison between the expression levels of IncRNAs in the blood samples of breast cancer patients compared with healthy individuals revealed that some IncRNAs (MEG3, NBAT1, NKILA, GAS5, EPB41L4A-AS2, ZFAS1, MVIH, Z38, and BC040587) were down regulated. In contrast, other IncRNAs (H19, SPRY4IT1, UCA1, AC026904.1, CCAT1) were up-regulated, significantly. It was shown that the expression levels of NKILA, NBAT1, and ZFAS1 IncRNAs were related to tumor size, and BC040587expression level related to age, node metastasis, tumor size, and grade $(P<0.05)$. The association between H19 and SPRY4-IT1 IncRNAs with HER-2 was confirmed statistically $(P<0.05)$. Our data highlighted the correlation of BC040587, H19, and SPRY4-IT1 IncRNAs with clinicopathological traits in breast cancer patients suggesting their future applications as novel biomarkers and therapeutic targets in breast cancer. In conclusion, circulating IncRNAs could consider as the prognostic and predictive markers in breast cancer.

\section{Introduction}

Breast cancer is the most common malignant disease, affecting one million women worldwide. ${ }^{1}$ In Iran, breast cancer is the first leading cause of cancer death in females, including $27 \%$ of all cancers with an age-standardized rate (ASR) 31 per 100000 . According to the latest statistics in Iran, 13776 new breast malignancies are identified in $2018 .{ }^{2}$ The high level of breast cancer mortality is due to a lack of diagnostic markers for early detection, mammography screening programs, and suitable molecular markers for targeted and effective treatment opportunity. Late diagnosis may lead to cancer metastasis with less than $25 \%$ in 5 -year survival. ${ }^{3}$

Breast cancer lacks biomarkers with high specificity and sensitivity for general screening. Therefore, it is essential to search for novel biomarkers. The circulating IncRNA levels in cancer patients evaluated many IncRNAs as potential biomarker. ${ }^{4}$ Growing evidence has shown that long non-coding RNA expression levels are deregulated in human cancers. There is a possibility of using IncRNAs as therapeutic targets or potential biomarkers to rapidly breast cancer diagnosis. ${ }^{5,6,7}$ Besides, recent findings reported that circulating IncRNA in body fluids can be noninvasive diagnostic biomarkers for some cancers. ${ }^{8}$ Previous studies have reported that some oncogenic IncRNAs are overexpressed in various types of cancers and can serve as a prognostic marker. Overexpression of colon cancer-associated transcript-1 (CCAT1) indicated its role in malignancies' pathogenesis. ${ }^{9}, 10,11$ Similarly, the oncogenic role of some IncRNAs confirmed by illustrating their up-regulation in breast cancer tissues compared to adjacent normal tissues. ${ }^{2}, 13,14,15,16,17$ Such as AC026904.1, Urothelial Carcinoma-associated 1 (UCA1), SPRY4 intronic transcript 1 (SPRY4-IT1), microvascular invasion in hepatocellular carcinoma (MVIH), Colon Cancer Associated Transcript 2 (CCAT2), promoter of CDKN1A antisense DNA damage activated RNA (PANDAR) and zinc finger antisense 1 (ZFAS1) and $\mathrm{H} 19$ IncRNA, is overexpressed in $73 \%$ of breast cancer tissues compared to healthy tissues. ${ }^{18}$ Besides, a series of experiments showed that knockdown of Z38 significantly inhibited tumor growth in breast cancer. ${ }^{9}$ We hypothesized that the mentioned IncRNAs might be up-regulated in breast cancer and act as an oncogene. According to previous researches, some IncRNAs function as tumor suppressor genes, and their down-regulation may proceed to invasion and metastasis and lessen the effectiveness of chemotherapeutic treatment. Neuroblastoma associated transcript-1 (NBAT1) behaved as a tumor-suppressor and down regulated in invasive breast cancer. ${ }^{20}$ Likewise, decreased expression levels of FGF14 antisense RNA 2 (FGF14-AS2), X inactive specific transcript (XIST), BC040587, and MEG3 in breast cancer tissue and cell lines compared with corresponding normal control were associated with

unfavorable survival in breast cancer. ${ }^{21,22,23}$ Meanwhile, down-regulation of IncRNAs such as NF-KB interacting IncRNA (NKILA), EPB41L4A antisense RNA 2 (EPB41L4A-AS2), and Growth arrest-specific transcript 5 (GAS5) inhibit breast cancer progression and may advance invasion and metastasis of breast cancer. ${ }^{16,24,25}$ There is controversy regarding down-regulation o up-regulation of IncRNAAK058003 in literature. ${ }^{26,27}$

There have been a limited number of early diagnoses of breast cancer in Iran, and there is an urgent need to develop an early diagnosis platform for public health professionals. In addition, there are few published reports of IncRNAs expression levels in breast cancer patients' blood. Therefore, in the current study, the expression profiles of twenty IncRNAs (H19, CCAT1, CCAT2, UCA1, SPRY4-IT1, 
AK058003, Z38, MVIH, XIST, PANDAR, GAS5, ITGB2-AS1, MEG3, AC026904.1, ZFAS1, NKILA, EPB41L4A-AS2, FGF14-AS2, NBAT1, BC040587) in blood samples of Iranian breast cancer patients and healthy females investigated by QRT-PCR. Then, the association of IncRNAs expression profiles with clinicopathological features of breast cancer patients was assessed.

\section{Results And Discussion}

qRT-PCR analyzed by REST software and presented in Table 3. The results showed the information on fold change of the down-regulated IncRNAs in the blood samples of breast cancer patients comparing to the healthy women as $(P<0.05)$ MEG3 $(0.216 \pm 0.026)$, NBAT1 $(0.233 \pm 0.051)$, NKILA $(0.453 \pm 0.087)$, GAS5 $(0.188 \pm 0.051), Z 38(0.487 \pm 0.113)$, AK058003 (0.455 \pm 0.1$), M V I H(0.502 \pm 0.122)$, EPB41L4A-AS2 (0.256 \pm 0.057$), B C 040587(0.260 \pm 0.038)$. On the other hand, the fold change of over-expressed IncRNAs $(P<0.05)$ are as follows: H19 (25.35 \pm 3.152$)$, SPRY4-IT1 (9.062 \pm 1.076$)$, CCAT1 (3.371 \pm 0.512$)$, UCA1 (2.817 \pm 0.461$)$, AC026904.1 (2.171 \pm 0.359$)$.

The expression level of twenty IncRNAs in blood samples of breast cancer patients showed in Fig. 1 and their expression compared with healthy normal women in Fig. 2.

Assessments of IncRNAs profiles association with clinicopathological features of breast cancer patients showed that the expression level of NKILA, NBAT1, and ZFAS1 IncRNAs were related to the tumor size. However, BC040587expression level was related to age, node metastasis, tumor size, and grade of breast cancer patients, and NBAT1 IncRNA expression was also correlated with the patients' age ( $P$ $<0.05)$. Furthermore, there is a statistical association between SPRY4-IT1 $(P=0.03)$ and H19 $(P=0.04)$ expression levels and HER-2 in cancer patients' blood samples. The correlation between other IncRNAs expression levels and clinicopathological features was not significant $(P>0.05)$.

The IncRNAs biomarker characterization could be beneficial for early detection and treatment in breast cancer. ${ }^{35}$ Increasing evidence represented the association of IncRNAs expressed in tumor tissues with cancer development or metastasis. ${ }^{7}$ At the same time, there are few reports of circulating IncRNAs in blood samples of cancer patients as shown in Table 4. We investigate and compare the expression levels of twenty IncRNAs in blood samples of breast cancer patients and healthy individuals, and then the correlation between IncRNAs deregulation and clinical characteristics was analyzed in this study.

Researchers revealed that the IncRNAs Z38 and MVIH expression levels increased in breast cancer tissues, and they showed a relation with stage and lymph node metastasis. ${ }^{10,13}$ However, the present study indicated that circulating Z38 $(0.487 \pm 0.113)$ and MVIH $(0.502 \pm$ 0.122) expression levels declined in breast cancer patients' blood samples. The expression levels of Z38 and MVIH in patients' blood and cancer tissue was different. The possible explanation for this phenomenon might be the different disease stages among various studies. Besides, the low circulating IncRNA levels compared to IncRNA levels in tissue specimens might be due to both the technical and biological determinants that impact circulating IncRNA levels. ${ }^{50}$

According to our results, there was a down-regulation in MEG3 expression level $(0.216 \pm 0.026)$ in blood samples of breast cancer patients compared to healthy individuals. Similarly, Sun et al. (2016) reported the MEG3 down-regulation in cancer tissues compared with adjacent normal tissues. ${ }^{51}$ They also reported that MEG3 expression level was significantly associated with stage and lymph node metastasis. The circulating NBAT1 level $(0.233 \pm 0.051)$ in breast cancer patients was also significantly decreased, which is in agreement with the Hu et al. (2015) report. ${ }^{20}$ Although the NBAT1 expression pattern significantly correlated with tumor size and patient age $(p<$ 0.05), other researchers represented its association with lymph node metastasis. ${ }^{20}$

The down-regulation of circulating EPB41L4A-AS2 $(0.256 \pm 0.057)$ proved to involve in tumorigenesis. Nevertheless, Xu et al. (2016) reported the relationship between expression levels and tumor grade, size, and disease stage. ${ }^{26}$ we did not observe any significant correlation between these characteristics and EPB41L4A-AS2 expression level. There was a report of IncRNA GAS5 down-regulation in breast cancer samples compared to adjacent healthy breast tissue. In the current study, we do not observe the association between GAS5 expression $(0.188 \pm 0.051)$ and lymph node metastasis, tumor size, and the histological grade was not significantly associated, which is in agreement with the study performed by Li et al. (2018). ${ }^{16}$

LncRNAs ZFAS1 and NKILA as tumor suppressors down- regulated in human breast tumors. ${ }^{33,}{ }^{36}$ In the current study, low ZFAS1 (0.0497 $\pm 0.066)$ and NKILA $(0.453 \pm 0.087)$ expression levels were significantly correlated with tumor size $(p<0.05)$.

The expression level of tumor suppressor BC040587 (0.26 \pm 0.038$)$ gene in breast cancer patients' blood samples was revealed. The same results from breast cancer tissue showed by Chi et al. (2014). ${ }^{22}$ It can be used as a prognostic indicator to assess tumor 
progression due to strongly associated BC040587 expression with tumor size, grade, and node.

A dramatic rise in the circulating H19-LncRNA expression level is shown in breast cancer patients compared to healthy individuals (25.350 \pm 3.152 ). Our findings approved the results of Jiao et al. (2018), who investigated the H19 expression levels in the plasma of breast cancer patients compared with healthy controls. ${ }^{38}$ Besides, Dugimont and Adriaenssens (2005) ${ }^{46}$ illustrated a correlation between H19 expression levels and pathological features such as lymph node metastasis, tumor grades, and the presence of estrogen and progesterone receptors that did not validate in the current research. On the other hand, we have found a positive correlation between $\mathrm{H} 19$ LncRNA expression level and HER-2 that indicated H19 as a potential regulator of proliferation in the HER2 enriched subtype.

Several studies demonstrated that SPRY4-IT1 promotes cell growth, invasion and inhibits apoptosis in several types of cancer, including breast cancer. ${ }^{13}$ This statement confirms by our finding that the expression levels of SPRY4-IT1 were significantly overexpressed in blood samples of breast cancer patients $(9.062 \pm 1.07)$ in comparison to healthy individuals. In contrast, Jiao et al. (2018) showed downregulation of IncRNA SPRY4-IT1 in breast cancer patients' plasma compared to healthy female controls. They used different primer pairs for SPRY4-IT1 amplification, and there is no information about patients' pathological traits. The results of Shi et al. (2015) investigated the expression levels of IncRNA SPRY4-IT1 in breast cancer tissues compared to adjacent normal tissues. ${ }^{13}$ According to Xiang et al. (2019), there is no significant relation between SPRY4-IT1 expression in BC tissues and molecular subtypes (ER/PR/HER2) of breast cancer ${ }^{47}$, found a significant relation between SPRY4-IT1 and HER-2.

In the same way, high expression of IncRNA CCAT1 (3.371 \pm 0.512$)$ was not correlated with other clinicopathological factors of breast cancer patients such as differentiation grade, age, tumor size, stage, and lymph node metastases $(P>0.05)$. Zhang et al. (2015) presented the same results and suggested that CCAT1 might function as an oncogenic IncRNA and serve as a potential prognostic marker in breast cancer. ${ }^{10}$

The UCA1 gene encodes for a IncRNA highly expressed in various carcinomas, including bladder, colorectal, and breast cancer, suggesting that UCA1 might serve as a potential biomarker for diagnostic purposes in the future. ${ }^{43}$ Meanwhile, in the present study, UCA1 was highly expressed in the blood samples of breast cancer patients $(2.817 \pm 0.461)$ and was not associated with other clinicopathological factors of breast cancer patients.

Similarly, Li et al. (2018) reported that AC026904.1 was highly expressed in metastatic breast cancer and closely associated with poor prognosis. ${ }^{48}$ In our results, the up-regulation with a high expression level $(2.171 \pm 0.359)$ was also shown.

According to the Heatmap (Fig. 2), the expression level of ITGB2-AS1 upregulated; however, a significant up-regulation was not shown in the REST results. ITGB2-AS1 could promote the invasion of breast cancer cells, and because the majority of our patients are in the initiation stages of cancer development, significant up-regulation could be suppressed. ${ }^{3}$

\section{Conclusion}

Identifying highly sensitive and specific IncRNAs for the early diagnosis and prognosis of breast cancer invasion and metastasis remains a hard task. Many studies have explored biomarkers in tumor biopsies, suggesting many candidate RNAs and proteins as biomarkers in various cancers. The detection of IncRNAs in body fluids, such as blood or urine, could be considered non-invasive cancer biomarkers. In this study, blood samples were used to detect suitable IncRNAs (Table 4), while their functions remain to be proved in larger patients' cohort.

Our results showed that the levels of whole blood IncRNAs H19, SPRY4 -IT1, CCAT1, UCA1, and AC026904.1 were all significantly increased. LncRNAs MEG3, NBAT1, NKILA, GAS5, Z38, AK058003, MVIH, EPB41L4A-AS2, and BC040587 were significantly decreased in breast cancer patients, indicating that these IncRNAs might be valuable for breast cancer diagnosis in the blood. The down-regulation of BC040587 and up-regulation of H19 and SPRY4-IT1 were associated with clinicopathological traits, suggesting a potential role for breast cancer clinical management markers. Further investigations complete the follow-up process to study the prognostic value of these biomarkers.

\section{Methods}

\section{Patient specimens}


Blood samples of 30 breast cancer patients were collected from different hospitals (Sina, Farmaniyeh, Moheb Kosar) in other parts of Tehran, Iran from, April to August 2019. All the clinicopathological features of samples were obtained from the medical records and are shown in Table 1. None of the patients had undergone any preoperative cancer treatments, including radiotherapy or chemotherapy. Thirty blood samples of healthy women were collected from the same age ranges of patients. We use "healthy normal" as the absence of any apparent disease as defined by Aagaard et al. (2012) ${ }^{28}$. We first screened volunteer blood donors using criteria based on health history, including the absence of systemic diseases such as cancer, hypertension, diabetes, and autoimmune disorders or immunodeficiency. Exclusion criteria included a body mass index (BMI) outside the range of 18.5 to $24.9 \mathrm{~kg} / \mathrm{m}^{2}$, not being pregnant, not consuming alcohol, not suffering from infectious diseases, and specified chronic diseases. Furthermore, we excluded individuals under certain medical treatments such as corticosteroids, immunosuppressive agents, antibiotics, or probiotics within the last six months.

Fresh blood was quickly transferred on ice to the Pasteur Institute of Iran. The Ethics Committee of the Institute of Pasteur of Iran (IR.PII.REC.1395.111) approved this research. The Written informed consent was obtained from all the participants.

All experiments were performed in accordance with the relevant guidelines and regulations by the Pasteur Institute committee that approved the research, (Ethical approval IR.PII.REC.1397.008).

Methods were performed in accordance with relevant guidelines/regulations, and confirming that informed consent was obtained from all participants.

\section{RNA isolation and CDNA synthesis}

Total RNAs were extracted from blood samples using the Jena Bioscience kit (Germany) according to the manufacturer's instructions. Only samples with an A260:A280 ratio between 1.8 and 2.1 were considered for further analysis recorded by the microplate reader (BioTek, USA). The cDNA was synthesized using the BIO FACT kit according to the manufacturer's protocol. Briefly, $2 \mu \mathrm{g}$ total RNA, $1 \mu \mathrm{g}$ Oligodt, $10 \mu \mathrm{l}$ Mastermix, and $7 \mu \mathrm{l}$ RNase Free $\mathrm{dH}_{2} \mathrm{O}$, were combined in a total reaction volume of $20 \mu \mathrm{l}$ and incubated at room temperature for $5 \mathrm{~min}$, followed by $50^{\circ} \mathrm{C}$ for $30 \mathrm{~min} .{ }^{15}$

\section{Quantitative real-time PCR}

The used primers in this study were shown in Table 2. The primers some used for the first time and are mentioned in the table and designed by AllelID, Gene Runner, Baecon designer, and Primer 3 software. The designed primers were finally checked by using the Beacon designer or Primer-Blast on the NCBI website.

The expression levels of IncRNAs were quantified by Eva Green premix (WisPure qPCR Master). A $2 \mu$ l cDNA, 10 $\mu$ l Master-mix, $6 \mu l$ water, and $1 \mu \mathrm{l}$ of each primer (Metabion, Germany) were used for qPCR. The real-time PCR conditions were as follows: $95^{\circ} \mathrm{C}$ for $10 \mathrm{~min}, 40$ cycles of $95^{\circ} \mathrm{C}$ for $10 \mathrm{sec}, 60^{\circ} \mathrm{C}$ for $15 \mathrm{sec}$, and $72^{\circ} \mathrm{C}$ for $20 \mathrm{sec}$, which was done by Rotor-Gene Q (Corbett, Germany). All experiments were performed in double, and LinReg PCR software (version 2014) was used to calculate each chart's Ct amount for. The REST program (2009 software) was used to calculate Fold changes. The Heatmap depiction of IncRNAs expression levels (columns) of patients compared with healthy normal women was illustrated using http://www.heatmapper.ca/ website.

\section{Statistical analysis}

The statistical program for SPSS 18.0 (SPSS, Chicago, IL, United States) was employed to analyze all the data. Data are expressed as the mean \pm standard deviation. For comparisons between two groups, the Student's $t$-test was used while comparing multiple groups using one-way analysis of variance (ANOVA). The $\chi 2$ test was applied to analyze the association between IncRNAs expression and clinicopathological status. P-value $<0.05$ was considered to indicate a statistically significant difference in all cases.

\section{Declarations}

\section{Competing interests}

The authors declare no competing interests

Funding: The study was supported by a research grant (No. 1046) from Pasteur Institute of Iran

Ethical approval: IR.PII.REC.1397.008

Page 5/13 
Conceptualization: M.O., Data analysis and wrote the manuscript: Z.P., Sample collection and processing: F.A .A. and M.Y., Supervision: M.O. and M.A. discussed the design of the experiments and the results M.O., Z.P., and M.A.

\section{References}

1. DeSantis CE, Ma J, Goding Sauer A, et al. Breast cancer statistics, 2017, racial disparity in mortality by state. CA Cancer J Clin 2017; 67(6): 439-448.

2. Zendehdel K. Cancer Statistics in I.R. Iran in 2018. Basic \& Clinical Cancer Research 2019; 11(1): 1-4.

3. Liu M, Gou L, Xia J, et al. LncRNA ITGB2-AS1 Could Promote the Migration and Invasion of Breast Cancer Cells through UpRegulating ITGB2. Int J Mol Sci 2018; 19; 1866.

4. Oloomi M, Bouzari S, Mohagheghi MA, et al. Molecular Markers in Peripheral Bloodof Iranian Women with Breast Cancer. Cancer Microenvironment 2013; 6:109-116.

5. Wu ZJ, Li Y, Wu YZ, et al. Long non-coding RNA CCAT2 promotes the breast cancer growth and metastasis by regulating TGF-beta signaling pathway. Eur Rev Med Pharmacol Sci 2017; 21: 706-14.

6. Xi J, Feng J, Li Q, et al. The long non-coding RNA IncFOXO1 suppresses growth of human breast cancer cells through association with BAP1. Int J Oncol; 2017: 50: 1663-70.

7. Zhang M, Wu WB, Wang ZW, et al. IncRNA NEAT1 is closely related with progression of breast cancer via promoting proliferation and EMT. Eur Rev Med Pharmacol Sci 2017; 21: 1020-6.

8. Shi, T, Gao, G, Cao, Y. 2016. Long Noncoding RNAs as Novel Biomarkers Have a Promising Future in Cancer Diagnostics. Disease Markers 2016; 1-10

9. Deng R, Liu B, Wang Y, et al. High Expression of the Newly Found Long Noncoding RNA Z38 Promotes Cell Proliferation and Oncogenic Activity in Breast Cancer. J Cancer 2016; 7(5): 576-586.

10. Zhang ZF, Liu T, Li Y, Li S. Overexpression of long non-coding RNA CCAT1 is a novel biomarker of poor prognosis in patients with breast cancer. Int J Clin Exp Pathol 2015; 8(8): 9440-9445.

11. Xin Y, Li Z, Shen J, et al. CCAT1: a pivotal oncogenic long non-coding RNA in human cancers. Cell Prolif 2016; 49: 255-260.

12. Lei $\mathrm{B}, \mathrm{Xu} \mathrm{S}$, Liang $\mathrm{X}$, et al. Long non-coding RNA MVIH is associated with poor prognosis and malignant biological behavior in breast cancer. Tumor Biol 2016; 37: 5257-

13. Shi Y, Li J, Liu Y, et al. The long noncoding RNA SPRY4-IT1 increases the proliferation of human breast cancer cells by upregulating ZNF703 expression. Cancer 2015; 14.

14. Huang J, Zhou N, Watabe K, et al. Long non-coding RNA UCA1 promotes breast tumor growth by suppression of p27 (Kip1). Cell Death Dis 2014; 5:e1008.

15. Cai Y, He J, Zhang D. Long noncoding RNACCAT2 promotes breast tumor growth by regulating the Wnt signaling pathway. OncoTargets and Therapy 2015; 8: 2657-2664

16. Li S, Zhou J, Wang Z, et al. Long noncoding RNA GAS5 suppresses triple negative breast cancer progression through inhibition of proliferation and invasion by competitively binding miR-196a-5p. Biomed Pharmacother 2018; 104: 451-457.

17. Yang Z, Sun Y, Liu R, et al. Plasma long noncoding RNAs PANDAR, FOXD2-AS1, and SMARCC2 as potential novel diagnostic biomarkers for gastric cancer. Cancer Manag Res 2019; 11: 6175-6184

18. Collette J, Bourhis XL, Adriaenssens E. Regulation of Human Breast Cancer by the Long Non-Coding RNA H19. Int J Mol Sci 2017; 18: 2319.

19. Jiang S, Chen R, Yu J, et al. Clinical significance and role of LKB1 in gastric cancer. Mol Med Rep 2016; 13: $249-256$.

20. Hu P, Chu J, Wu Y, et al. NBAT1 suppresses breast cancer metastasis by regulating DKK1 via PRC2. Oncotarget 2015; 6(32): 3241032425.

21. Yang F, Liu Y, Dong S, et al. A novel long non-coding RNA FGF14-AS2 is correlated with progression and prognosis in breast cancer. Biochem and Biophys Res Commun 2016; $470479 \mathrm{e} 483$.

22. Chi Y, Huang S, Yuan L, et al. Role of BC040587 as a predictor of poor outcome in breast cancer. Cancer Cell Int 2014; 14: 123. 
23. Zheng R, Lin S, Guan L, et al. Long non-coding RNA XIST inhibited breast cancer cell growth, migration, and invasion via miR155/CDX1 axis. Biochem Biophys Res Commun 2018; 498(4): 1002-1008.

24. Liu B, Sun L, Liu Q, et al. A Cytoplasmic NF-kappaB Interacting Long Noncoding RNA Blocks IkappaB Phosphorylation and Suppresses Breast Cancer Metastasis. Cancer cell 2015; 27: 370-381.

25. Xu S, Wang P, You Z, et al. The long non-coding RNA EPB41L4A-AS2 inhibits tumor proliferation and is associated with favorable prognoses in breast cancer and other solid tumors. Oncotarget 2016; 7(15): 20704-20717.

26. He X., Zheng Y, Zhang Y, et al. Long non-coding RNA AK058003, as a precursor of miR-15a, interacts with HuR to inhibit the expression of $Y$-synuclein in hepatocellular carcinoma cells. Oncotarget 2017; 8(6): 9451-9465.

27. He K, Wang P. Unregulated long non-coding RNA-AK058003 promotes the proliferation, invasion and metastasis of breast cancer by regulating the expression levels of the gamma-synuclein gene. Exp Ther Med 2015; 9: 1727-1732.

28. Aagaard K, Petrosino J, Keitel W, et al. The Human Microbiome Project strategy for comprehensive sampling of the human microbiome and why it matters. FASEB J 2013; 27: 1012-22.

29. Zhang Y, Zhu Z, Huang S, et al. LncRNA XIST regulates proliferation and migration of hepatocellular carcinoma cells by acting as miR-497-5p molecular sponge and targeting PDCD4. Cancer Cell Int 2019; 19: 198.

30. Lai Y., Chen Y, Lin Y, et al. Down-regulation of LncRNA CCAT1 enhances radiosensitivity via regulating miR-148b in breast cancer. Cell Biol Int 2018; 42: 227-236.

31. Gu L, Lu LS, Zhou DL, et al. UCA1 promotes cell proliferation and invasion of gastric cancer by targeting CREB1 sponging to miR-5903p. Cancer Med 2018; 7(4): 1253-

32. Ye Y, Gu J, Liu P, et al. Long non-coding RNA SPRY4-IT1 reverses cisplatin resistance by downregulating MPZL-1 via suppressing EMT in NSCLC. OncoTargets and therapy. 2020; 13: 2783.

33. Nie ZL, Wang YS, Mei YP, et al. Prognostic significance of long noncoding RNA Z38 as a candidate biomarker in breast cancer. J Clin Lab Anal 2018; 32(1): e22193.

34. Wang A, Du L, Jiang K, et al. Long noncoding RNA microvascular invasion in hepatocellular carcinoma is an indicator of poor prognosis and a potential therapeutic target in gastric cancer. J Cancer Res Ther 2019; 15(1): 126-131.

35. Wu W, Chen F, Cui X, et al. LncRNA NKILA suppresses TGF-b-induced epithelial- mesenchymal transition by blocking NF-jB signaling in breast cancer. Int J Cancer 2018; 1-12.

36. Fan S, Fan C, Liu N, et al. Downregulation of the long non-coding RNA ZFAS1 is associated with cell proliferation, migration and invasion in breast cancer. Mol Med Rep 2018; 17: 6405-6412.

37. Dai J, Xu LJ, Han GD, et al. Down-regulation of long non-coding RNA ITGB2-AS1 inhibits osteosarcoma proliferation and metastasis by repressing Wnt/ $\beta$-catenin signaling and predicts favourable prognosis, Artif Cell Nanomed Biotechnol 2018; 46(sup3): S783-S790.

38. Jiao ZY, Tian Q, Li N, Wang HB, Li KZ. Plasma long non-coding RNAs (IncRNAs) serve as potential biomarkers for predicting breast cancer. Eur Rev Med Pharmacol Sci 2018; 22(7): 1994-9.

39. Salama, Esraa A., Adbeltawab, Reda E., El Tayebi,Hend M., XIST and TSIX: Novel Cancer Immune Biomarkers in PD-L1Overexpressing Breast Cancer Patients. Front Oncol 2020; 1-13.

40. Han L, Ma P, Liu SM, Zhou X. Circulating long noncoding RNA GAS5 as a potential biomarker in breast cancer for assessing the surgical effects. Tumor Biol 2016; 37(5): 6847-54.

41. Ali MA, Shaker OG, Alazrak M, et al. Association analyses of a genetic variant in long non-coding RNA MEG3 with breast cancer susceptibility and serum MEG3 expression level in the Egyptian population. Cancer Biomark 2020; 28: 1-5.

42. Sang Y, Tang J, Li S, et al. LncRNA PANDAR regulates the G1/S transition of breast cancer cells by suppressing p16 ${ }^{\text {INK4A }}$ Sci Rep $2016 ; 6,22366$.

43. Tuo, YL, Li, XM, Luo, J. Long noncoding RNA UCA1 modulates breast cancer cell growth and apoptosis through decreasing tumor suppressive miR-143. Eur Rev Med Pharmacol Sci 2015; 19: 3403-3411.

44. Askarian-Amiri ME, Crawford J, French JD, et al. SNORD-host RNA Zfas1 is a regulator of mammary development and a potential marker for breast cancer. RNA 2011; 17: 878-891.

45. Lottin S, Adriaenssens E, Dupressoir T, et al. Overexpression of an ectopic $\mathrm{H} 19$ gene enhances the tumorigenic properties of breast cancer cells. Carcinogenesis 2002; 23: 1885-1895.

46. Dugimont T and Adriaenssens E. H19 mRNA-like noncoding RNA promotes breast cancer cell proliferation through positive control by E2F1. J Biol Chem 2005; 280: 29625-29636.

Page $7 / 13$ 
47. Xiang Y, Chen Y, Shi Y, Wu X, Hao R, Li Q, Li D. Upregulation of the long non-coding RNA SPRY4-IT1 predicts poor prognosis in breast cancer. Int J Clin Exp Pathol 2019; 12(3):1003-1008.

48. Li GY, Wang W, Sun JY, et al. Long non-coding RNAs AC026904.1 and UCA1: a "one-two punch" for TGF- $\beta$-induced SNAI2 activation and epithelial-mesenchymal transition in breast cancer. Theranostics 2018; 8 (10): 2846-2861.

49. Sun L, Li Y, Yang B. Downregulated long noncoding RNA MEG3 in breast cancer regulates proliferation, migration and invasion by depending on p53's transcriptional activity. Biochem Biophys Res Commun 2016; 478: 323-329.

50. Schlosser, K., Hanson, J., Villeneuve, P. et al. Assessment of Circulating LncRNAs Under Physiologic and Pathologic Conditions in Humans Reveals Potential Limitations as Biomarkers. Sci Rep 2016; 6:

\section{Tables}

Table 1- clinicopathological features of 30 Iranian healthy women and 30 breast cancer patients.

\begin{tabular}{|c|c|}
\hline Clinicopathological Features & Frequency \\
\hline Healthy womenAge $\leq 5050<$ & 1713 \\
\hline \multicolumn{2}{|l|}{ Cancer patientsAge } \\
\hline$\leq 50$ & 16 \\
\hline $50<$ & 14 \\
\hline Tumor size (cm) & 18 \\
\hline \multicolumn{2}{|l|}{$<2.5$} \\
\hline $2.5 \leq$ & 12 \\
\hline \multicolumn{2}{|l|}{ Differentiation grade } \\
\hline $\mathrm{G} 1 / \mathrm{G} 2$ & 19 \\
\hline G3 & 11 \\
\hline \multicolumn{2}{|l|}{ Lymph node metastasis } \\
\hline Positive & 14 \\
\hline Negative & 16 \\
\hline \multirow{2}{*}{\multicolumn{2}{|c|}{$\begin{array}{l}\text { TNM staging } \\
\text { (Tumor, Node, Metastases) }\end{array}$}} \\
\hline & \\
\hline $\mathrm{I} / \mathrm{II}$ & 21 \\
\hline III & 9 \\
\hline \multicolumn{2}{|l|}{ Histological type } \\
\hline IDC & 28 \\
\hline ILC & 2 \\
\hline Estrogen receptor (ER)PositiveNegativeUnknown & 10173 \\
\hline Progesterone receptor (PR)PositiveNegativeUnknown & 10173 \\
\hline HER2 statuesPositiveNegativeUnknown & 3243 \\
\hline
\end{tabular}

Table 2- Primers used for IncRNAs expression levels in breast cancer. 


\begin{tabular}{|c|c|c|c|c|c|}
\hline Name & Location & $\begin{array}{l}\text { Tumor } \\
\text { Suppressor/Oncogene }\end{array}$ & Function & Primer sequence & References \\
\hline H19 & $11 p 15.5$ & oncogene & $\begin{array}{l}\text { miRNA sponge } \\
\text { miRNA precursor }\end{array}$ & $\begin{array}{l}\text { GAGCCGATTCCTGAGTC } \\
\text { GCCTTCCTGAACACCTTA }\end{array}$ & $\begin{array}{l}\text { In this } \\
\text { study }\end{array}$ \\
\hline XIST & $\begin{array}{l}\text { inactive X- } \\
\text { chromosome }\end{array}$ & & $\begin{array}{l}\text { X-chromosome } \\
\text { silencing and cell } \\
\text { growth }\end{array}$ & $\begin{array}{l}\text { CTCCAGATAGCTGGCAACC } \\
\text { AGCTCCTCGGACAGCTGTAA }\end{array}$ & (29) \\
\hline GAS5 & $1 q 25.1$ & tumor suppressor & $\begin{array}{l}\text { interaction with } \\
\text { the mTOR } \\
\text { pathway }\end{array}$ & $\begin{array}{l}\text { CAAGCCGACTCTCCATACCT } \\
\text { CTTGCCTGGACCAGCTTAAT }\end{array}$ & $(16)$ \\
\hline PANDAR & $\begin{array}{l}\sim 5 \mathrm{~kb} \\
\text { upstream of } \\
\text { CDKN1A }\end{array}$ & & $\begin{array}{l}\text { regulation of } \\
\text { G1/S transition }\end{array}$ & $\begin{array}{l}\text { GTGGCCAAAGGATCTGACGA } \\
\text { TCCCAACAAACAAGGGGTGG }\end{array}$ & $(17)$ \\
\hline CCAT1 & $8 q 24.21$ & oncogene & miRNA sponge & $\begin{array}{l}\text { TCATGTCTCGGCACCTTTCC } \\
\text { TCATTACCAGCTGCCGTGTT }\end{array}$ & (30) \\
\hline CCAT2 & $8 q 24.21$ & oncogene & $\begin{array}{l}\text { regulation of } \\
\text { Wnt/catenin } \\
\text { signaling } \\
\text { pathway }\end{array}$ & $\begin{array}{l}\text { TCATGTCTCGGCACCTTTCC } \\
\text { AAGAGGGAGGTATCAACAGAGAC }\end{array}$ & $\begin{array}{l}\text { In this } \\
\text { study }\end{array}$ \\
\hline UCA1 & 19p13.12 & oncogene & $\begin{array}{l}\text { microRNA } \\
\text { sponge; } \\
\text { regulation of } \\
\text { KLF4- } \\
\text { KRT6/13signaling } \\
\text { pathway and } \\
\text { Metastasis }\end{array}$ & $\begin{array}{l}\text { TTGTCCCCATTTTCCATCAT } \\
\text { TTTGCCAGCCTCAGСTTAAT }\end{array}$ & (31) \\
\hline BC040587 & $3 q 13.31$ & tumor suppressor & unknown & $\begin{array}{l}\text { AATGACTTCACAGCAAGG } \\
\text { GAGATGCTGCTGGTGAGTAG }\end{array}$ & $\begin{array}{l}\text { In this } \\
\text { study }\end{array}$ \\
\hline SPRY4-IT1 & $\begin{array}{l}\text { chromosome } \\
5\end{array}$ & oncogene & $\begin{array}{l}\text { Promote cell } \\
\text { proliferation, } \\
\text { increase } \\
\text { invasion and } \\
\text { metastasis, } \\
\text { inhibit apoptosis, } \\
\text { advanced clinical } \\
\text { stage, } \\
\text { poor prognosis }\end{array}$ & $\begin{array}{l}\text { CGATGTAGGATTCCTTTCA } \\
\text { AGCCACATAAATTCAGCAGA }\end{array}$ & (32) \\
\hline NBAT1 & $6 p 22.3$ & tumor suppressor & $\begin{array}{l}\text { mediating } \\
\text { transcriptional } \\
\text { silencing }\end{array}$ & $\begin{array}{l}\text { TCAGCAGAAACGGCACGAT } \\
\text { AGATGACCCAGGCACCTCC }\end{array}$ & (20) \\
\hline AK058003 & $10 q 22$ & oncogene & $\begin{array}{l}\text { regulating - } \\
\text { synuclein gene } \\
\text { (SNCG) } \\
\text { expression }\end{array}$ & $\begin{array}{l}\text { ACTGGTTCATAGTTAGGCTGGAT } \\
\text { GGGAACAAAGATGGTTTCTACGT }\end{array}$ & (26) \\
\hline Z38 & $3 q 11.2$ & oncogene & unknown & $\begin{array}{l}\text { AGGTAAAAGGAACTGGCAACGC } \\
\text { AGTGGGATTGTGGAGACGGTGT }\end{array}$ & (33) \\
\hline FGF14-AS2 & $13 q 33.1$ & tumor suppressor & unknown & $\begin{array}{l}\text { AGGTTCATAGTTGCCAGAC } \\
\text { AGTTCCAGTTACCATCTTCA }\end{array}$ & (21) \\
\hline MVIH & $10 q 22$ & oncogene & unknown & $\begin{array}{l}\text { AGCACTTTGGAAGGCTTAGACA } \\
\text { GAGACAGGATTTAGCCGTGTTG }\end{array}$ & (34) \\
\hline
\end{tabular}




\begin{tabular}{|c|c|c|c|c|c|}
\hline \multirow{2}{*}{$\begin{array}{l}\text { EPB41L4A- } \\
\text { AS2 }\end{array}$} & \multirow[t]{2}{*}{$5 p 22.2$} & \multirow[t]{2}{*}{ tumor suppressor } & \multirow[t]{2}{*}{ unknown } & TCAAAACTACGTCTGATGCCAAA & \multirow[t]{2}{*}{$(25)$} \\
\hline & & & & CGGAGCAGGTGCAATCTGT & \\
\hline \multirow[t]{2}{*}{ NKILA } & \multirow[t]{2}{*}{ 20q13 } & \multirow[t]{2}{*}{ tumor suppressor } & \multirow{2}{*}{$\begin{array}{l}\text { Suppressing NF- } \\
\text { KB activation and } \\
\text { EMT }\end{array}$} & ACCACTAAGTCAATCCCAGGTG & \multirow[t]{2}{*}{ (35) } \\
\hline & & & & AACCAAACCTACCCACAACG & \\
\hline ZFAS1 & $20 q 13.13$ & tumor suppressor & & $\begin{array}{l}\text { CCAGTGGTGACTCCCTCTTCCAAAGAG } \\
\text { GTTCAGGAAGCCATTCGTTCT }\end{array}$ & (36) \\
\hline \multirow[t]{2}{*}{ AC026904.1 } & \multirow[t]{2}{*}{$8 q 11.21$} & & & GACTTAGGACCACTTAGCA & \multirow{2}{*}{$\begin{array}{l}\text { In this } \\
\text { study }\end{array}$} \\
\hline & & & & CCACGATACCCACTTCTT & \\
\hline \multirow[t]{2}{*}{ MEG3 } & \multirow[t]{2}{*}{$14 q 32.2$} & \multirow[t]{2}{*}{ tumor suppressor } & \multirow{2}{*}{$\begin{array}{l}\text { Proliferation and } \\
\text { EMT }\end{array}$} & CTGGCATAGAGGAGGTGA & \multirow{2}{*}{$\begin{array}{l}\text { In this } \\
\text { study }\end{array}$} \\
\hline & & & & TGGAGGTGAGGAAGGAAG & \\
\hline \multirow[t]{2}{*}{ ITGB } & \multirow[t]{2}{*}{ 10p11.22 } & \multirow[t]{2}{*}{ oncogene } & \multirow{2}{*}{$\begin{array}{l}\text { Migration and } \\
\text { Invasion }\end{array}$} & TTAGTGGTCTGCGAAGGTG & \multirow[t]{2}{*}{ (37) } \\
\hline & & & & AGGAGATGGAACGAGGAAA & \\
\hline
\end{tabular}

Table 3- The fold changes of the analyzed RT-PCR by REST software.

\begin{tabular}{|c|c|c|c|c|c|c|c|}
\hline Gene & Type & Reaction Efficiency & Expression & Std. Error & $95 \%$ C.I. & $\mathrm{P}(\mathrm{H} 1)$ & ) Result \\
\hline B-actin & REF & 1.0282 & 1.000 & & & & \\
\hline MEG3 & TRG & 0.7708 & 0.216 & $0.026 \cdot 1.740$ & $0.002 \cdot 9.802$ & 0.000 & DOWN \\
\hline PANDAR & TRG & 0.7738 & 0.807 & $0.180 \cdot 3.278$ & $0.037 \cdot 26.264$ & 0.487 & \\
\hline NBAT-1 & TRG & 0.7722 & 0.233 & $0.051-0.975$ & $0.004-6.089$ & 0.000 & DOWN \\
\hline NKILA & TRG & 0.7733 & 0.453 & $0.087 \cdot 2.083$ & $0.023-11.091$ & 0.009 & DOWN \\
\hline GAS5 & TRG & 0.7738 & 0.188 & $0.051 \cdot 0.656$ & $0.011 \cdot 4.350$ & 0.000 & DOWN \\
\hline FGF14-AS2 & TRG & 0.7738 & 0.686 & $0.113 \cdot 3.719$ & $0.026 \cdot 57.691$ & 0.288 & \\
\hline EPB41L4A-AS2 & TRG & 0.7738 & 0.256 & $0.057-1.166$ & $0.013-4.324$ & 0.000 & DOWN \\
\hline ZFAS1 & TRG & 0.7738 & 0.497 & $0.066-2.909$ & $0.009 \cdot 20.059$ & 0.063 & \\
\hline XIST & TRG & 0.7738 & 1.450 & $0.229 \cdot 4.948$ & $0.051 \cdot 57.549$ & 0.236 & \\
\hline $\mathrm{AC} 026904.1$ & TRG & 0.7738 & 2.171 & $0.359 \cdot 10.998$ & $0.077-81.194$ & 0.021 & 1 UP \\
\hline UCA1 & TRG & 0.7738 & 2.817 & $0.461-16.845$ & $0.087-102.285$ & 0.001 & 1 UP \\
\hline MVIH & TRG & 0.7738 & 0.502 & $0.122 \cdot 2.367$ & $0.010 \cdot 13.191$ & 0.036 & 5 DOWN \\
\hline AK058003 & TRG & 0.7738 & 0.455 & $0.100 \cdot 2.108$ & $0.016 \cdot 16.481$ & 0.011 & 1 DOWN \\
\hline CCAT1 & TRG & 0.7733 & 3.371 & $0.512 \cdot 19.406$ & $0.097 \cdot 171.676$ & 0.001 & 1 UP \\
\hline CCAT2 & TRG & 0.7738 & 0.548 & $0.096 \cdot 3.003$ & $0.022 \cdot 13.706$ & 0.052 & \\
\hline ITGB2-AS1 & TRG & 0.7733 & 0.704 & $0.137 \cdot 3.519$ & $0.015 \cdot 28.774$ & 0.314 & \\
\hline Z38 & TRG & 0.7738 & 0.487 & $0.113 \cdot 1.919$ & $0.022 \cdot 9.374$ & 0.011 & 1 DOWN \\
\hline $\mathrm{H} 19$ & TRG & 0.7729 & 25.350 & $3.152 \cdot 181.475$ & $0.540-1.677 .874$ & 0.000 & UP \\
\hline SPRY4-IT1 & TRG & 0.7729 & 9.062 & $1.076-64.342$ & $0.237-703.962$ & 0.000 & UP \\
\hline BC040587 & TRG & 0.7738 & 0.260 & $0.038 \cdot 1.501$ & 0.00711 .964 & 0.000 & DOWN \\
\hline
\end{tabular}

Table 4- Current and previous reports of the circulating IncRNAs levels in breast cancer. 


\begin{tabular}{|c|c|c|c|}
\hline \multirow[t]{2}{*}{ LncRNAs } & \multicolumn{3}{|l|}{ Expression levels in: } \\
\hline & Tumor tissue & Blood samples & Blood samples (this study) \\
\hline H19 & Up-regulated 45 & Up-regulated ${ }^{38}$ & Up-regulated (25.350 \pm 3.152$)$ \\
\hline XIST & Down-regulated ${ }^{23}$ & Up-regulated 39 & No significant change \\
\hline GAS5 & Down-regulated ${ }^{16}$ & Down-regulated 40 & Down-regulated $(0.188 \pm 0.051)$ \\
\hline PANDAR & Up-regulated ${ }^{42}$ & No report & No significant change \\
\hline CCAT1 & Up-regulated 10,11 & No report & Up-regulated (3.371 \pm 0.512) \\
\hline CCAT2 & Up-regulated $^{15}$ & No report & No significant change \\
\hline UCA1 & Up-regulated ${ }^{43}$ & No report & Up-regulated $(2.817 \pm 0.461)$ \\
\hline ВC040587 & Down-regulated 22 & No report & Down-regulated $(0.26 \pm 0.038)$ \\
\hline SPRY4-IT1 & Up-regulated ${ }^{49}$ & Down-regulated ${ }^{38}$ & Up-regulated (9.062 \pm 1.07$)$ \\
\hline NBAT1 & Down-regulated ${ }^{20}$ & No report & Down-regulated $(0.233 \pm 0.051)$ \\
\hline AK058003 & Up-regulated 26,27 & No report & No significant change \\
\hline Z38 & Up-regulated $^{9}$ & No report & Down-regulated $(0.487 \pm 0.113)$ \\
\hline FGF14-AS2 & Down-regulated ${ }^{21}$ & No report & No significant change \\
\hline MVIH & Up-regulated ${ }^{12}$ & No report & Down-regulated $(0.502 \pm 0.122)$ \\
\hline EPB41L4A-AS2 & Down-regulated ${ }^{25}$ & No report & Down-regulated $(0.256 \pm 0.057)$ \\
\hline NKILA & Down-regulated ${ }^{35}$ & No report & Down-regulated $(0.453 \pm 0.087)$ \\
\hline ZFAS1 & Down-regulated 36,44 & No report & Down-regulated $(0.0497 \pm 0.066)$ \\
\hline AC026904.1 & Up-regulated ${ }^{48}$ & No report & Up-regulated (2.171 \pm 0.359) \\
\hline MEG3 & Down-regulated 49 & Down-regulated ${ }^{41}$ & Down-regulated $(0.216 \pm 0.026)$ \\
\hline ITGB & Up-regulated ${ }^{3}$ & No report & No significant change \\
\hline
\end{tabular}

\section{Figures}




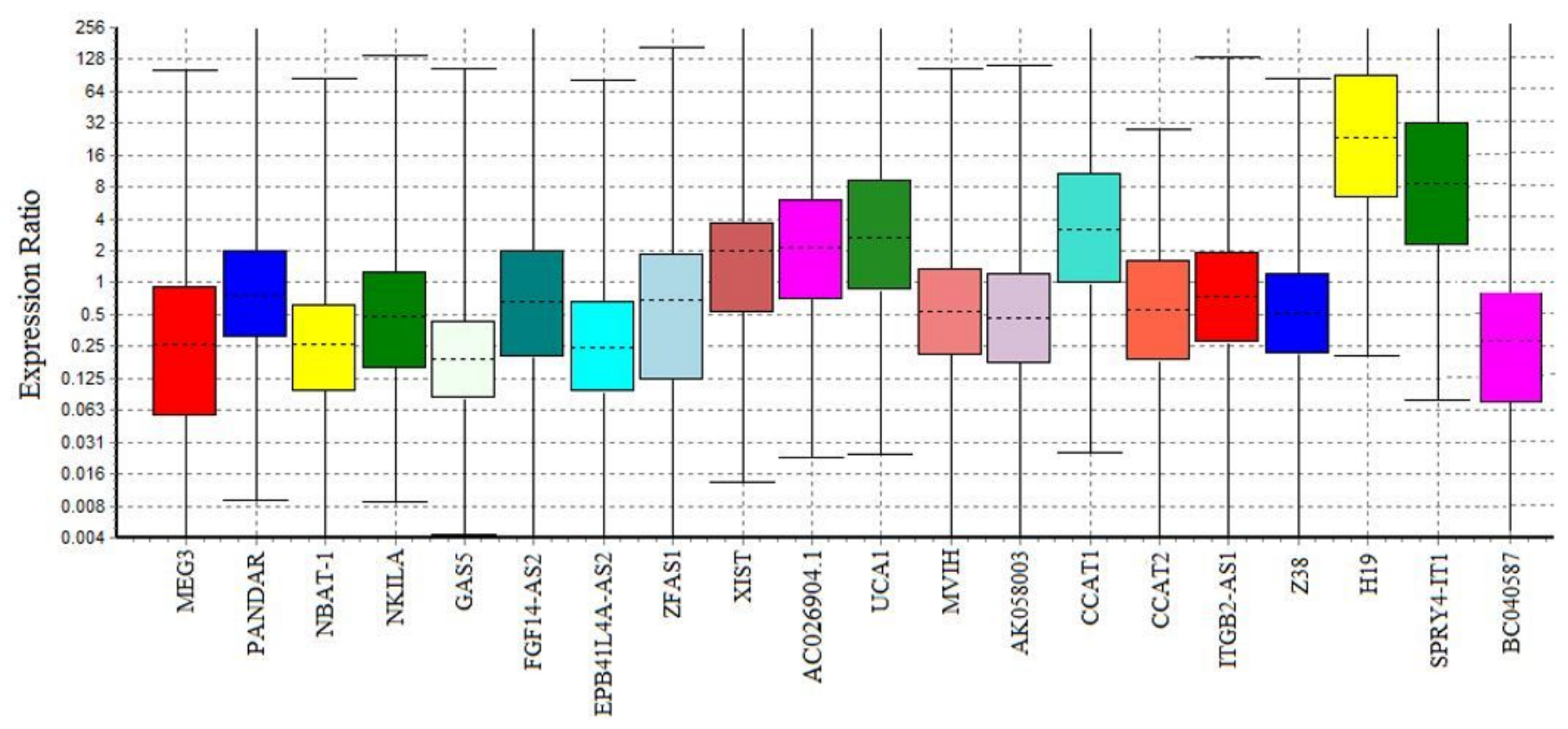

Figure 1

The IncRNAs expression levels in 20 blood samples of BC patients. Expression values are illustrated 2- $\Delta C T$ over the median of the healthy samples. 

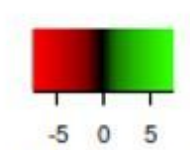

Column Z-Score

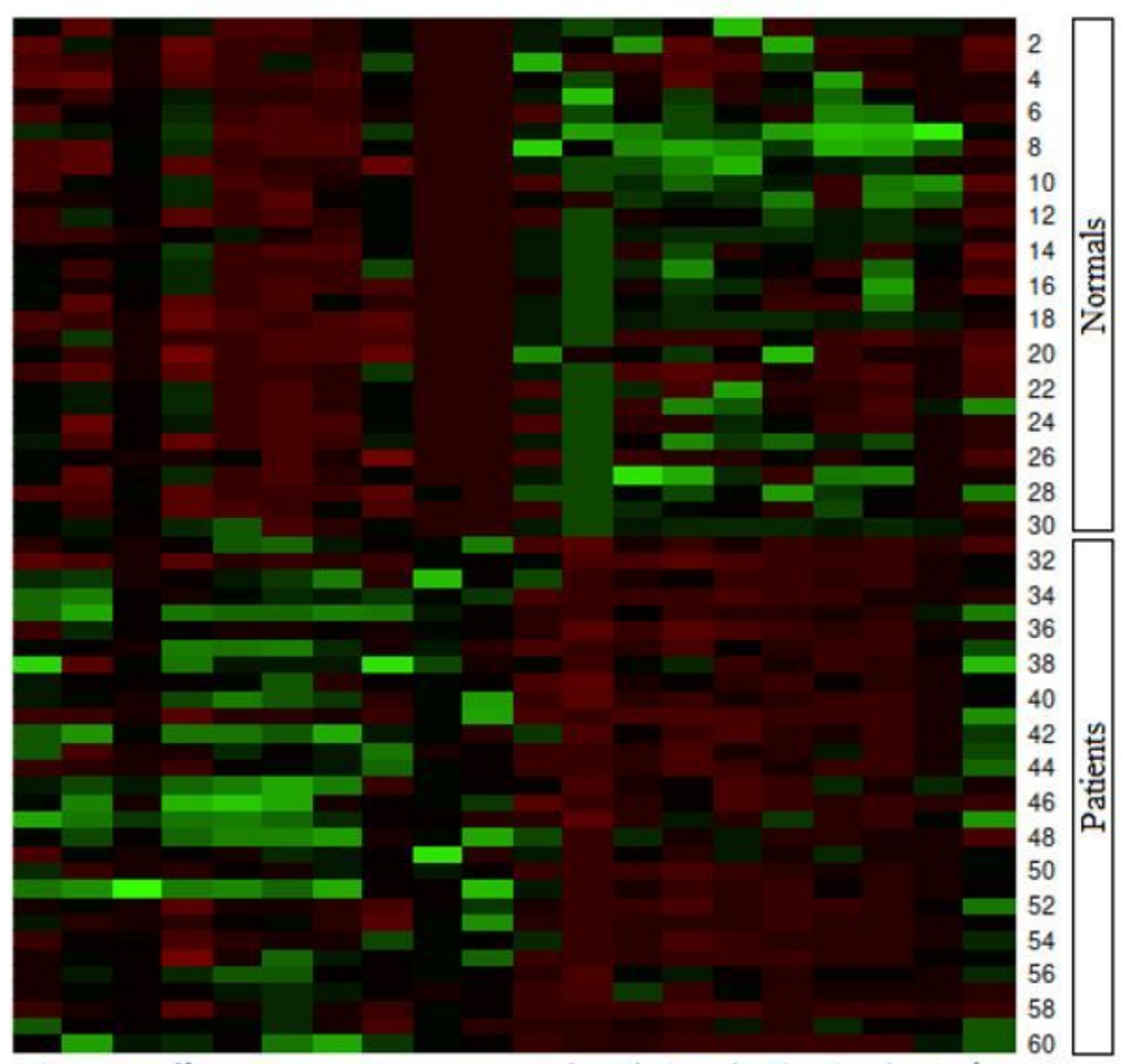

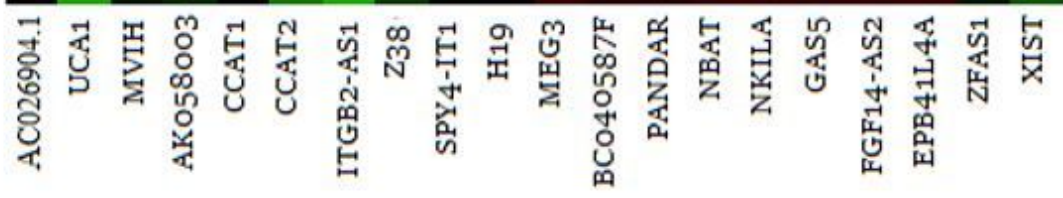

\section{Figure 2}

The Heatmap depicts IncRNAs expression levels (columns) in breast cancer patients compared with healthy normal women (rows). Expression values as $2-\Delta \mathrm{CT}$ are illustrated. 